Article

\title{
Blanding's Turtle (Emydoidea blandingii) Potential Habitat Mapping Using Aerial Orthophotographic Imagery and Object Based Classification
}

\section{Rebecca Barker and Douglas J. King *}

Geomatics and Landscape Ecology Laboratory, Department of Geography and Environmental Studies, Carleton University, 1125 Colonel By Drive, Ottawa, ON K1S 5B6, Canada;

E-Mail: barkerebecca@gmail.com

* Author to whom correspondence should be addressed; E-Mail: doug_king@carleton.ca; Tel.: +1-613-520-2600 ext. 8439; Fax: +1-613-520-4301.

Received: 14 November 2011; in revised form: 30 December 2011 / Accepted: 31 December 2011 / Published: 11 January 2012

\begin{abstract}
Blanding's turtle (Emydoidea blandingii) is a threatened species under Canada's Species at Risk Act. In southern Québec, field based inventories are ongoing to determine its abundance and potential habitat. The goal of this research was to develop means for mapping of potential habitat based on primary habitat attributes that can be detected with high-resolution remotely sensed imagery. Using existing spring leaf-off $20 \mathrm{~cm}$ resolution aerial orthophotos of a portion of Gatineau Park where some Blanding's turtle observations had been made, habitat attributes were mapped at two scales: (1) whole wetlands; (2) within wetland habitat features of open water, vegetation (used for camouflage and thermoregulation), and logs (used for spring sun-basking). The processing steps involved initial pixel-based classification to eliminate most areas of non-wetland, followed by object-based segmentations and classifications using a customized rule sequence to refine the wetland map and to map the within wetland habitat features. Variables used as inputs to the classifications were derived from the orthophotos and included image brightness, texture, and segmented object shape and area. Independent validation using field data and visual interpretation showed classification accuracy for all habitat attributes to be generally over $90 \%$ with a minimum of $81.5 \%$ for the producer's accuracy of logs. The maps for each attribute were combined to produce a habitat suitability map for Blanding's turtle. Of the 115 existing turtle observations, 92.3\% were closest to a wetland of the two highest suitability classes. High-resolution imagery combined with object-based classification and habitat suitability mapping methods such as those presented provide a much more spatially
\end{abstract}


explicit representation of detailed habitat attributes than can be obtained through field work alone. They can complement field efforts to document and track turtle activities and can contribute to species inventory planning, conservation, and management.

Keywords: Blanding's turtle; habitat; wetlands; remote sensing; orthophotos; object based classification

\section{Introduction}

Habitat loss and degradation are primary threats to amphibian and reptile populations [1]. Remote sensing of habitat attributes often uses abiotic and biotic spatial variables such as topography and vegetation type to characterize and map suitable habitat for a given species [2]. Land cover, which is a common attribute derived from remotely sensed data, can be used to infer habitat through implied relationships or through the explicit integration of other spatially referenced information (e.g., data points representing species presence) or environmental factors [3]. Alternatively, specific habitat attributes that directly or indirectly manifest in remotely sensed imagery can be extracted and combined in mapping of potential habitat. For example, using skyward hemispherical photography, Pasher et al. [4] found that Hooded Warbler (Wilsonia citrina) nest sites were spatially coincident with greater overhead canopy gap fraction. Based on this, canopy spatial heterogeneity, as measured in high-resolution satellite imagery, was shown to be a strong predictor of nest occurrence and potential habitat. This paper presents a study that took a similar species-centered approach for the threatened Blanding's turtle (Emydoidea blandingii) to classify and map potential habitat.

Blanding's turtle is a medium-sized freshwater reptile (up to about $27 \mathrm{~cm}$ length) with a rounded black carapace (shell) that is speckled with yellow dots (Figure 1; [5]). The plastron (belly of the shell) is yellow with square black blotches and its long neck, throat and chin are bright yellow [6]. Blanding's turtles are mainly aquatic predators that feed on insect larvae and nymphs, snails, leaches, crayfish, small fish, frogs and frog eggs, plant material and seeds from aquatic plants [7]. On land, Blanding's turtles eat vegetation, grasses, earthworms and slugs [8].

Preferred habitat includes permanent and temporary ponds, streams and wetlands [9-11] that are often small (e.g., less than 0.40 ha [12]). Upon spring emergence (late March through mid April), Blanding's turtles often bask in the sun through May to thermoregulate and increase their metabolism by sitting on wetland vegetation clumps, logs, or the wetland bank $[9,13,14]$. It is during this period that most observations are made because the turtles are more exposed. Marshes and small water habitats characterized by abundant vegetation are important for juveniles for refuge from predators as they are often found or captured in emergent sedges or the sedge-water interface [9,10,15-17]. From early June through July, pregnant females move to suitable sand or gravel nesting locations, often near ephemeral wetlands, roads, trails, or power line right-of-ways [9,12,18-20].

In summer, they often use marshes and highly productive ponds with abundant aquatic vegetation $[10,11,15,16,19]$. Emergent vegetation provides access to food resources and thermoregulation (warming in spring; cooling in summer) $[9,17]$. Sedges often grow in tussocks and can provide protective cover that remains cool in summer (e.g., Figure 2). Various studies have identified the importance of 
these types of vegetation forms [9,10,21] as opposed to ponds without aquatic vegetation or wetlands covered by cattail mats [11]. From late August to late October they move to a deeper wetland or pond to mate and hibernate [22], burying themselves in soft substrate [15]. Deep ponds provide warmer water temperatures and stable water levels that are critical for overwintering [11,23].

Figure 1. A Blanding's turtle. Observation made during 2008 population inventory in Québec [5]. Scale is approximate.

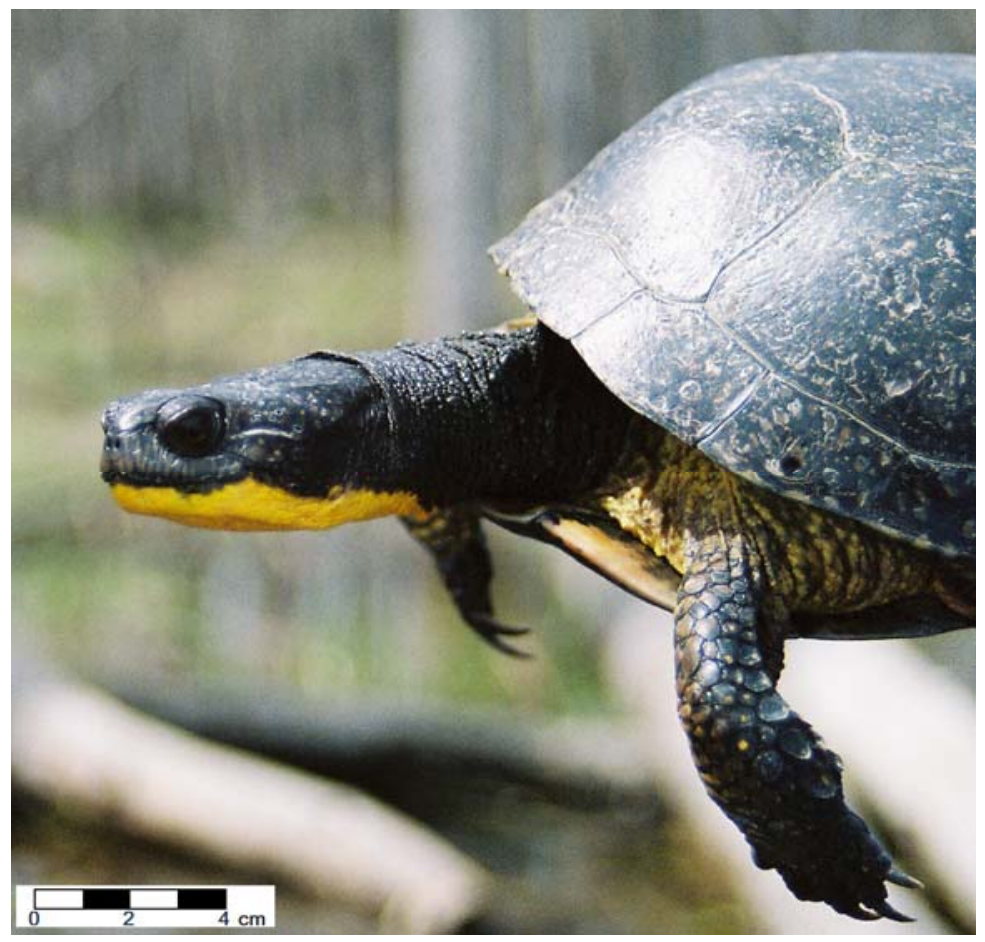

Blanding's turtle home range size varies from 1.5 ha to 63 ha $[22,24]$ and their mean travel distance can range from $489 \mathrm{~m}$ to $7 \mathrm{~km}$, but more commonly they travel up to $2 \mathrm{~km}[9-11,16,25]$. They have been found to spend up to $38 \%$ of the time in upland areas and travel up to $2 \mathrm{~km}$ between wetlands $(90 \mathrm{~m}-2,050 \mathrm{~m})[12,22]$. However, upland forest is generally considered as a land cover class of transit, usually of females to a nesting site. In these travels, they will often stop at vernal pools or at flooded areas in deciduous forest $[8,12,17]$. The upland landscape surrounding wetlands is therefore important to preserve for connectivity purposes [12,26] but was not the focus of this research on wetland habitat and within wetland habitat features.

The global range of the Blanding's turtle spans parts of North America, with $20 \%$ of the population residing in Canada. Reasons for its threatened status include: habitat loss and degradation [1,27]; susceptibility to road and predatory kill $[11,28]$ and other biological traits related to recruitment and environmental tolerance $[6,17,20,29]$.

Based on the above, there is potential to map Blanding's turtle habitat using high-resolution remote sensing. Wetlands, its primary broad habitat type, have been mapped for other purposes using methods ranging from visual interpretation of aerial photographs [30-32] to semi-automated classification of optical or radar imagery [33-37]. However, mapping of specific within wetland habitat features critical to the Blanding's turtle has only been done using manual interpretation of air photos $[9,12,26,38]$. The goal of this research was to map the spatial distribution of potential Blanding's turtle habitat based on 
attributes that are most often associated with reported observations and that have potential to be detected by high-resolution remote sensing imagery. From the literature analysis presented above, the selected habitat attributes were wetlands and within wetland water, vegetation and logs.

Figure 2. Sedge tussock in wetland. Such within wetland vegetation is an important Blanding's turtle habitat indicator. Scale is approximate.

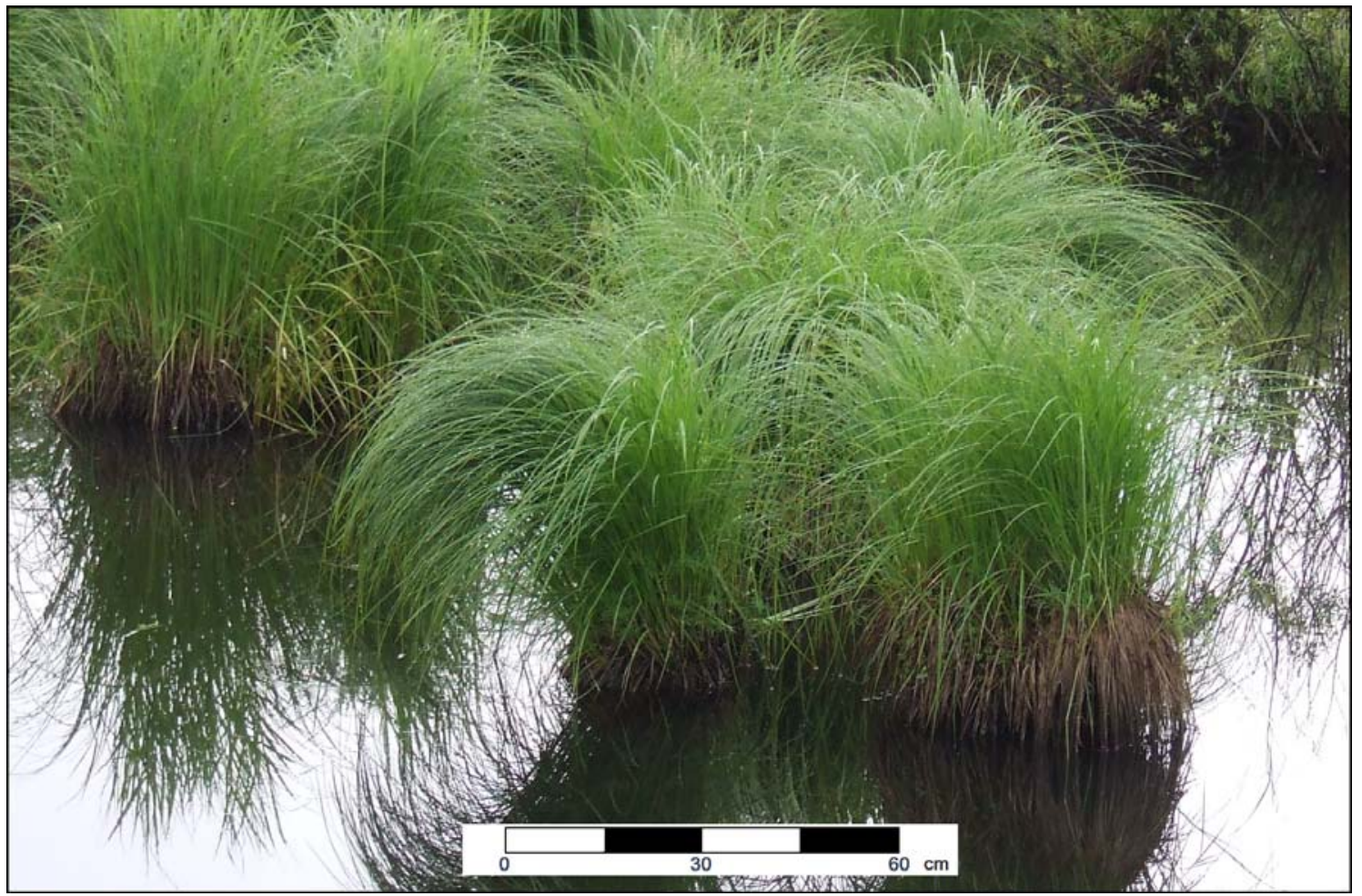

\section{Study Area and Previous Blanding's Turtle Observations}

This research was conducted in Gatineau Park, Québec, Canada, a $361 \mathrm{~km}^{2}$ protected area [39] centered at $45^{\circ} 30^{\prime} \mathrm{N}, 75^{\circ} 52^{\prime} \mathrm{W}$ that is comprised mostly of forest and wetlands (Figure 3; [40-42]). One goal of park management is to protect species at risk and implement recovery programs. When the Blanding's turtle was designated as threatened in 2005 there was little known about the size and distribution of the Québec population [6,25] except from a 1996-1999 inventory conducted outside the park near the Ottawa River (Figure 4, yellow outline, [18,43-46]). In 2007, additional field inventory was conducted in a specific area within Gatineau Park (Figure 4, purple outline) that augmented previous opportunistic observations [18]. Based on this, the study area for this research was selected as the area outlined in red in Figures 3 and 4. Figure 4 shows the accumulated observations to 2010 and identifies (red arrow) a hypothesized corridor between the northwest portion of the park and the Ottawa River wetlands [43].

Wetland vector data available for the study area were compiled by Ducks Unlimited Canada [47], and included the following datasets: (1) Québec Topographic Database (BDTQ) [48] with 82 wetlands; (2) the Conservation Atlas of Wetlands [49] with 14 wetlands mapped; (3) National Topographic Database (NTDB) with eight wetlands (three that don't overlap with data sources 1 and 2 above) [45], and (4) 282 water polygons (lakes) from NTDB (several overlapping other mapped wetlands from data 
sources above) [45]. However, field observation found small wetlands between about $100 \mathrm{~m}^{2}$ and $1,000 \mathrm{~m}^{2}$ that had not been mapped in these sources. It was therefore expected that the high-resolution air photos would facilitate mapping of these and provide an improved representation of the spatial distribution of potential Blanding's turtle habitat.

Figure 3. The approximate extents of the $16 \times 10 \mathrm{~km}$ study area (red outline) shown with respect to Canada, the province of Québec and Gatineau Park (central green area). Adapted from [40-42].

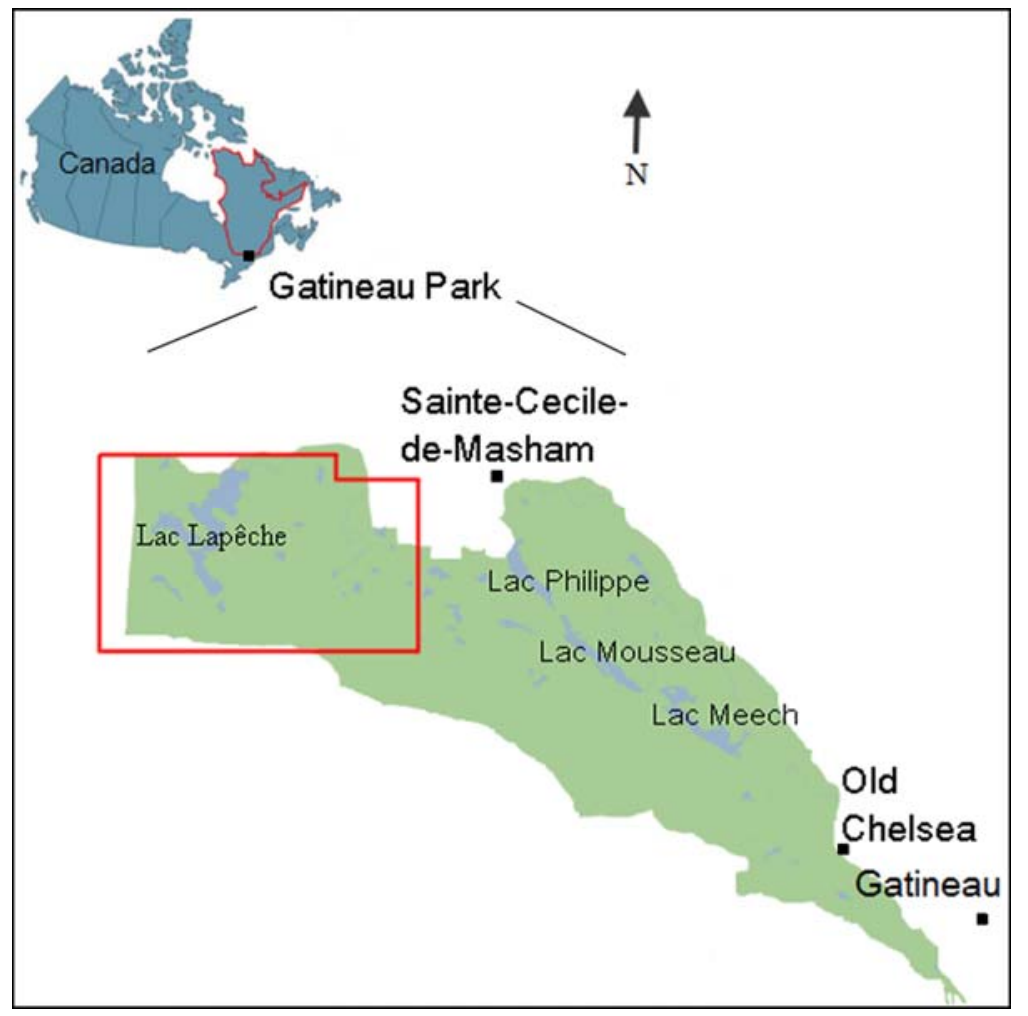

\section{Materials and Methods}

\subsection{Field Site Selection and Data Acquisition}

The map sources described above and spring 2007 leaf-off digital aerial orthophotos (described in Section 3.2) were used to locate wetlands to survey and plan field routes. For the purposes of this study, wetlands were defined as areas with standing water in spring, including small ponds, some being ephemeral, as well as areas with typical wetland vegetation of grasses, sedges, and cattails (Typha spp.). Inundated forest areas were excluded because they were not expected to be easily mapped due to the often significant presence of submerged or floating leaf litter, which had similar spectral and spatial image properties to adjacent non-inundated forest areas. The large lake in the center of the study area was also excluded as it was not expected to be suitable habitat.

Wetlands were visually identified, delineated in a GIS and categorized into priority levels for field survey based on the: (1) presence of more than approximately $100 \mathrm{~m}^{2}$ of open water as, below this threshold, interpretation of wetlands from the orthophotos was not believed to be reliable due to confusion with tree shadows, and literature has shown Blanding's wetland habitat to be typically larger 
than this (e.g., [12]); (2) presence of within wetland vegetation with moderate cover (e.g., 25-75\%) being higher priority than no vegetation or large per cent cover [11,14]; (3) presence of logs (at least $1-2$ in small wetlands, more in larger wetlands) $([6,50,51])$; and (4) need to represent the variety of wetland conditions and types in the study area for collection of sample training data for classification.

One hundred and seventy wetland field sites were visited between June and August 2008. Non-differential GPS with an expected horizontal accuracy of under $10 \mathrm{~m}$ [52] was used to navigate to selected wetlands and to geo-reference observation locations. Descriptions of each wetland, including vegetation types and approximate vegetation cover in $10 \%$ intervals were recorded and field photos were taken with a view angle perpendicular to the shore for later reference in classification training and validation.

Figure 4. Study area (red outline) in relation to the other primary nearby population (yellow outline) and the hypothesized ecological corridor between them (red arrow). Adapted from [18,43-46]. The purple rectangle shows an area of clustered observations near a road and system of trails.

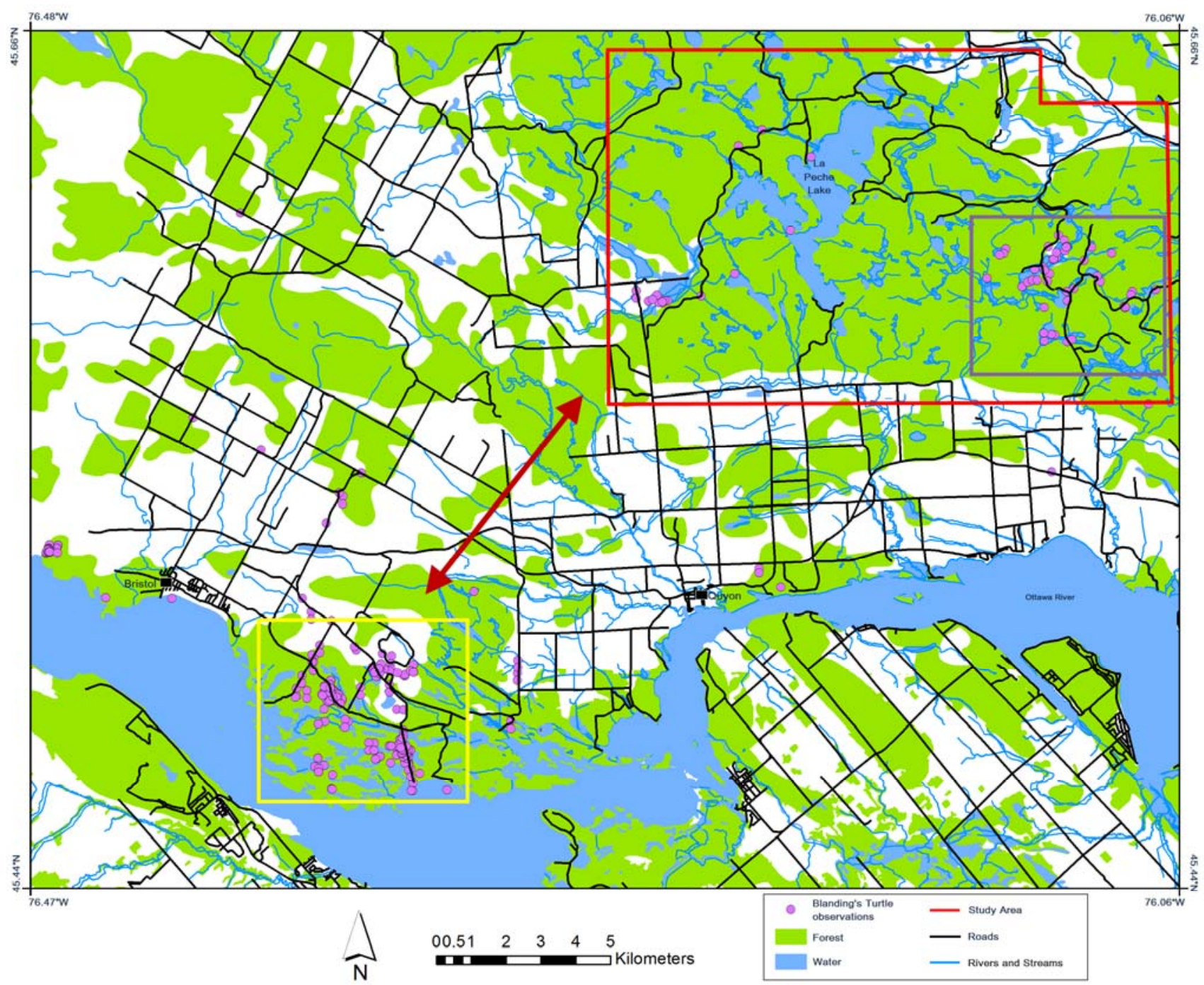




\subsection{Acquisition, Processing and Classification of High Resolution Digital Orthophotos}

It was determined that high-resolution satellite imagery, while providing good spectral information, would not provide the spatial resolution needed to detect and identify very small wetlands and within wetland vegetation and logs. Also, leaf-off imagery was expected to be more suitable than summer imagery because, in examination of 2007 summer airborne digital camera imagery with $0.25 \mathrm{~m}$ pixels for another area in Gatineau Park [53], it was evident that deciduous forest foliage can overtop and hide portions of wetlands from view by an overhead sensor. Consequently, the existing leaf-off air photos mentioned above were adopted for this study.

They were $23 \mathrm{~cm}$ format colour photos that had been acquired 6 May 2007 between 12:00 and 16:30 local time using Wild RC-20 and Zeiss Top 15 cameras flown simultaneously in two aircraft. The lens focal length was $152.4 \mathrm{~mm}$ and the average scale was $1: 16,000$ resulting in $2 \mathrm{~km} \times 2 \mathrm{~km}$ coverage per photo. The photos had been digitized into 8-bit $20 \mathrm{~cm}$ nominal pixel size red, green and blue spectral bands. Although the exact band centers and bandwidths were not known, standard color film was used, which typically has significant overlap in spectral sensitivity between the color layers [54]. The photos had been orthorectified and combined into a mosaic with positional accuracy of better than $1 \mathrm{~m}$ [29]. In total, for the $16 \mathrm{~km} \times 10 \mathrm{~km}$ study area, 38 photos were used in this research. A $4 \mathrm{~km} \times 2 \mathrm{~km}$ area ( 2 photos) in the northeast corner was excluded (see Figure 4 ) because it was outside the park boundary.

\subsection{Object-Based Segmentation and Classification of Wetlands and Within Wetland Habitat Features}

The goal of segmentation was to produce spatial entities representing wetlands, and within wetland features of water, vegetation, and logs. There has been an abundance of literature identifying the benefits of object classification (e.g., [55-58]), including additional image object attributes that can be used as input variables (e.g., texture, size and shape; inter-object topological information). eCognition software ([59]; now distributed by Trimble Inc.), was used as it offers several segmentation algorithms and over 100 different feature expressions that can be implemented in sequential classification rules. The multi-resolution segmentation algorithm was applied in the processing steps described in Sections 3.3.1 and 3.3.2. It is a region growing technique that locally minimizes the average heterogeneity of an image object for a given resolution. Objects are grown simultaneously across the scene based on spectral similarity of pixels and the contrast of an object with neighbouring objects. It was implemented using a top down approach where the higher scale (larger) objects are typically broad land cover types that are divided into lower level (smaller) objects until all targeted classes are identified $[60,61]$. A key unitless scale parameter is related to the image pixel size; larger scale values result in larger delineated objects. It is also related to the parameters of 'colour' (spectral information such as object mean brightness) and 'shape' [58,59]. For brevity, their detailed definitions are not presented here. Each is weighted from 0 to 1 with their respective weights summing to 1.0. The shape parameter has two sub-parameters, smoothness (of object borders) and compactness (in relation to a circle) [59]. In implementation, iterative testing of the parameter weights is commonly required until the resulting segments best match the desired landscape objects $[55,57,62]$. 
The main landcover classes were first segmented at a coarse object scale to classify wetlands and non-wetlands and later a finer object scale was used to identify thematic classes. In the second segmentation phase the potential wetland entities were segmented and classified into water and non water. The non water class objects were allocated into two classes, wetland vegetation and logs (based on parameters described in Section 3.3.2). The interactive software interface allowed for quick testing to be conducted on image subsets. The results could be visually assessed with confidence due to the very high spatial resolution of the imagery. Taking this approach, a series of steps, outlined below and in Figure 5, was implemented to produce and refine a wetland map followed by segmentation and classification of within wetland habitat features.

\subsubsection{Wetland Segmentation and Classification}

As the mosaic file was large ( 38 photos $\times 286 \mathrm{Mb} /$ photo $=10.9 \mathrm{~Gb}$, or 10.9 billion pixels), object based segmentation of the entire mosaic was not possible with the available computing power. Thus, an initial maximum likelihood pixel-based classification (MLC) was conducted to remove as much of the non wetland pixels as possible. In terms of image brightness, the distributions for moderately bright senescent spring wetland vegetation, deciduous forest leaf litter, and tree trunks overlapped significantly in each spectral band as did the histograms for darker features such as water, shadow and coniferous forest. Consequently, image texture was used to discriminate these classes. In the leaf-off imagery, trunks, branches and shadows created a texture distinct from that of wetland vegetation as shown in Figure 6. Tests were conducted of several Grey Level Co-occurrence Matrix (GLCM) and Grey Level Difference Vector (GLDV) [63] texture metrics extracted from the red band (it visually showed the greatest texture differences between land cover types) using omni-directional pixel pair sampling in window sizes of $3 \times 3,5 \times 5,11 \times 11$, and $25 \times 25$. From these, $5 \times 5$ GLDV Angular Second Moment (ASM) was found visually to best discriminate the features noted above. It was input to a supervised MLC using multiple training polygons for classes of water, wetland vegetation, deciduous forest, coniferous forest/shadow, power line corridor and agriculture (a small area in the corner of the mosaic). Training polygons were selected to be dispersed throughout the mosaic and representative of the range of conditions that could be visually discerned within the high-resolution imagery. The resulting classification was aggregated into two classes, Potential Wetland (i.e., pixels classified as water or wetland vegetation) and other. This eliminated most of the upland areas and the output wetland map was checked to ensure that no visually interpretable wetlands were eliminated.

The MLC wetland map was then refined through object segmentation and classification. As small coniferous/shadow pixels were often misclassified as small wetlands, the two class MLC wetland map was segmented using a scale parameter value of 10 , to delineate small objects about the size of these features. The colour value was set at 0.8 to give priority over shape, as the image was binary. However, within the shape parameter, the compactness value was set high, at 0.8, (with smoothness low) given the compact nature of shadows in relation to many of the small water bodies. The segments produced were then classified as coniferous/shadow or wetland based on their distance from the mean brightness value of training samples collected for each class. Classified shadow segments were then assigned to the other class while the pixels in the classified wetland segments were merged with the larger set of potential wetlands pixels. 
Figure 5. Image classification steps to produce segmented and classified wetlands and within wetland habitat features of water, vegetation and logs. Rectangles are image products; ellipses are processes. MLC = maximum likelihood classification. OBSC $=$ object-based segmentation and classification. For each segmentation, the scale value (S) is given. For each classification the discriminating variable type is given. $\mathrm{T}=$ data threshold as described in the text. $\mathrm{DN}=$ image brightness digital number. $\mathrm{L}=$ length. $\mathrm{W}=$ width.

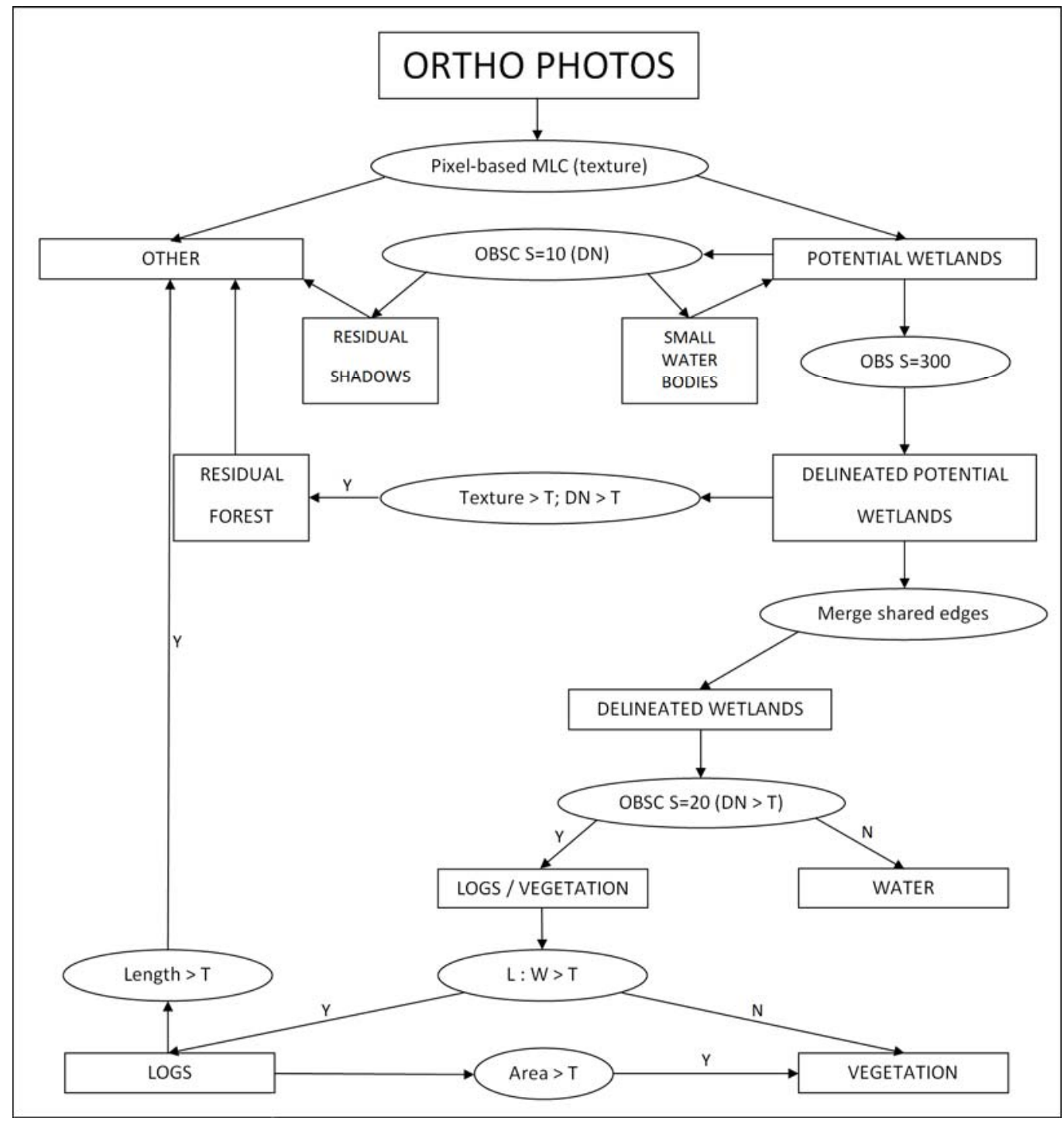

The potential wetland map at this stage was still comprised of pixels from the MLC and not objects, so segmentation was conducted to delineate the wetlands. The scale value was set to be 300 to delineate whole wetlands. Values above 300 produced objects comprised of more than one wetland while values of 100 and 200 segmented smaller objects within wetlands. Image brightness (colour $=0.8$ ) was weighted more than object shape (0.2) in defining segment boundaries, as the wetlands were bright while their masked out surroundings were black. For shape, objects were defined more by the degree of boundary smoothness (value $=0.9$ ) than their compactness (value $=0.1$ ) as was expected for these large land cover entities.

Following this, some residual erroneous forest segments were removed (assigned to Other) in two steps. First, after iterative testing, segments with GLCM Contrast texture of greater than 200 DN (i.e., 
high texture) were found to be forest and were removed. This texture metric was derived from sample pairs at 45 degrees to each other to approximately align with the tree shadow angle and resulting texture of deciduous forest (Figure 6) and it was calculated from all pixels in each segment (i.e., not using a moving window). Second, the few remaining residual forest segments were removed using a brightness threshold $(\mathrm{DN}>120)$ as their mean brightness was higher than wetland segments which included water.

Figure 6. Leaf-off orthophoto examples of deciduous forest (left) and examples of two extensive sections of senescent wetland vegetation that border open water sections of wetlands or streams.

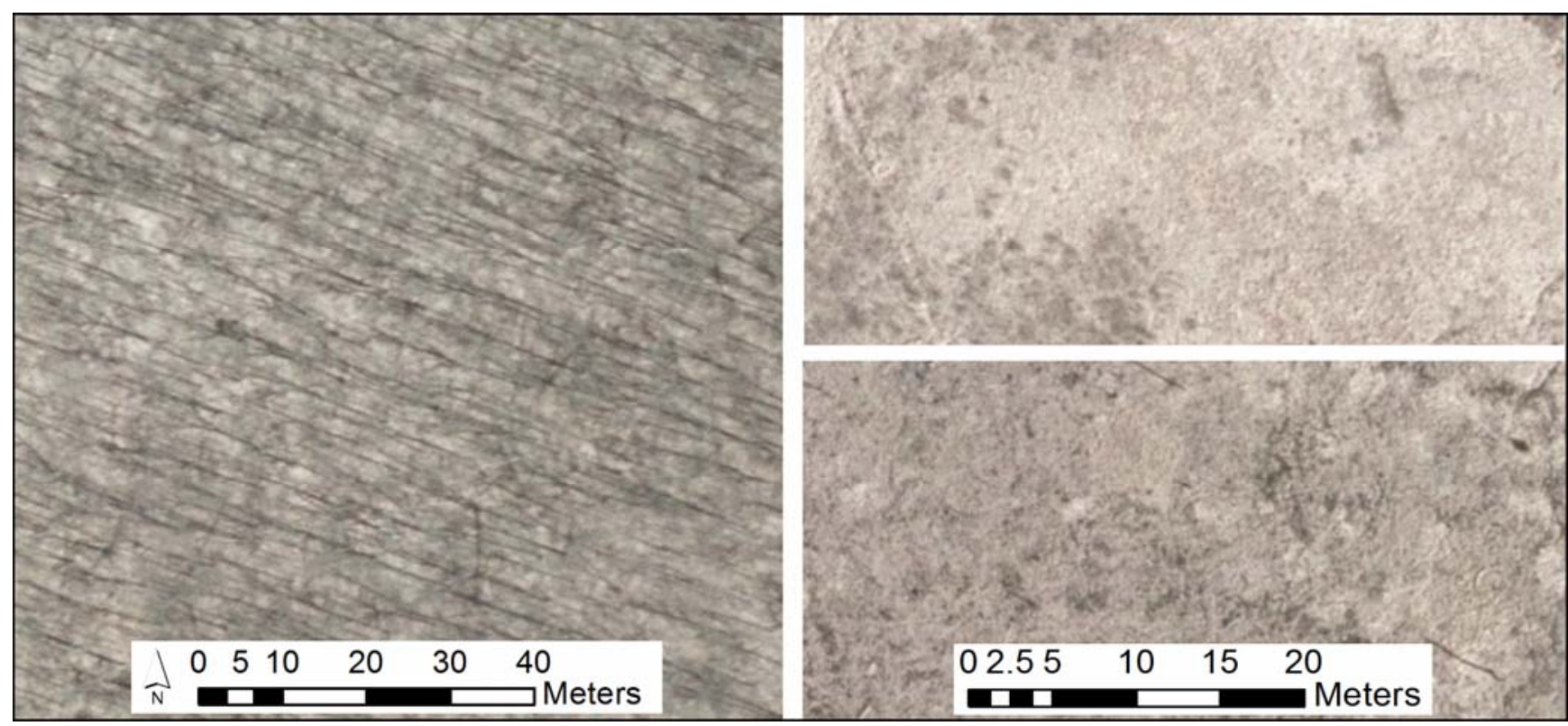

In the final wetland mapping step, wetland segments enclosed by a common boundary were merged into whole wetlands. The wetland map was then used to classify wetland habitat attributes as described below.

\subsubsection{Segmentation and Classification of Within Wetland Habitat Features: Water, Vegetation, Logs}

Image segmentation using the red spectral band was conducted within the wetland objects created above to delineate within wetland water, vegetation and logs. Through iterative testing of the scale, color/shape and smoothness/compactness parameters, optimal values were determined for each. Given the very high resolution of the imagery and interactive software interface, visual assessment of multiple segmentation results was straightforward and efficient to implement. Figure 7 shows the impact of the scale parameter in a portion of a wetland in the red band. Segmented objects representing logs and vegetation patches (brighter objects) are shown at three scale values: 100, 50, and 20. A scale value of 20 was selected as it was visually evident that smaller values often produced multiple segments per log or vegetation patch, while larger values did not accurately delineate individual logs or delineate the edge between wetland vegetation and water. Color and shape weights of 0.6 and 0.4 , respectively, were found to be optimal. Brightness was weighted stronger than shape due to the significant differences between the brighter vegetation or logs and the darker water. However, shape 
was deemed to be important given the shape differences between the three habitat features, so a significant though smaller weight was selected. For the shape sub parameters, object compactness was found to be more important than boundary smoothness in delineating vegetation patches and logs and weights of 0.7 and 0.3 for compactness and smoothness, respectively, were found to be optimal. These color and shape weights were used for all three segmentations in Figure 7.

Figure 7. Example segmentation of a portion of a wetland in the red band to determine the optimal scale parameter value for the within wetland classes of log and wetland vegetation (both bright) versus water (dark). ( $\mathrm{SP}=$ Scale Parameter.)

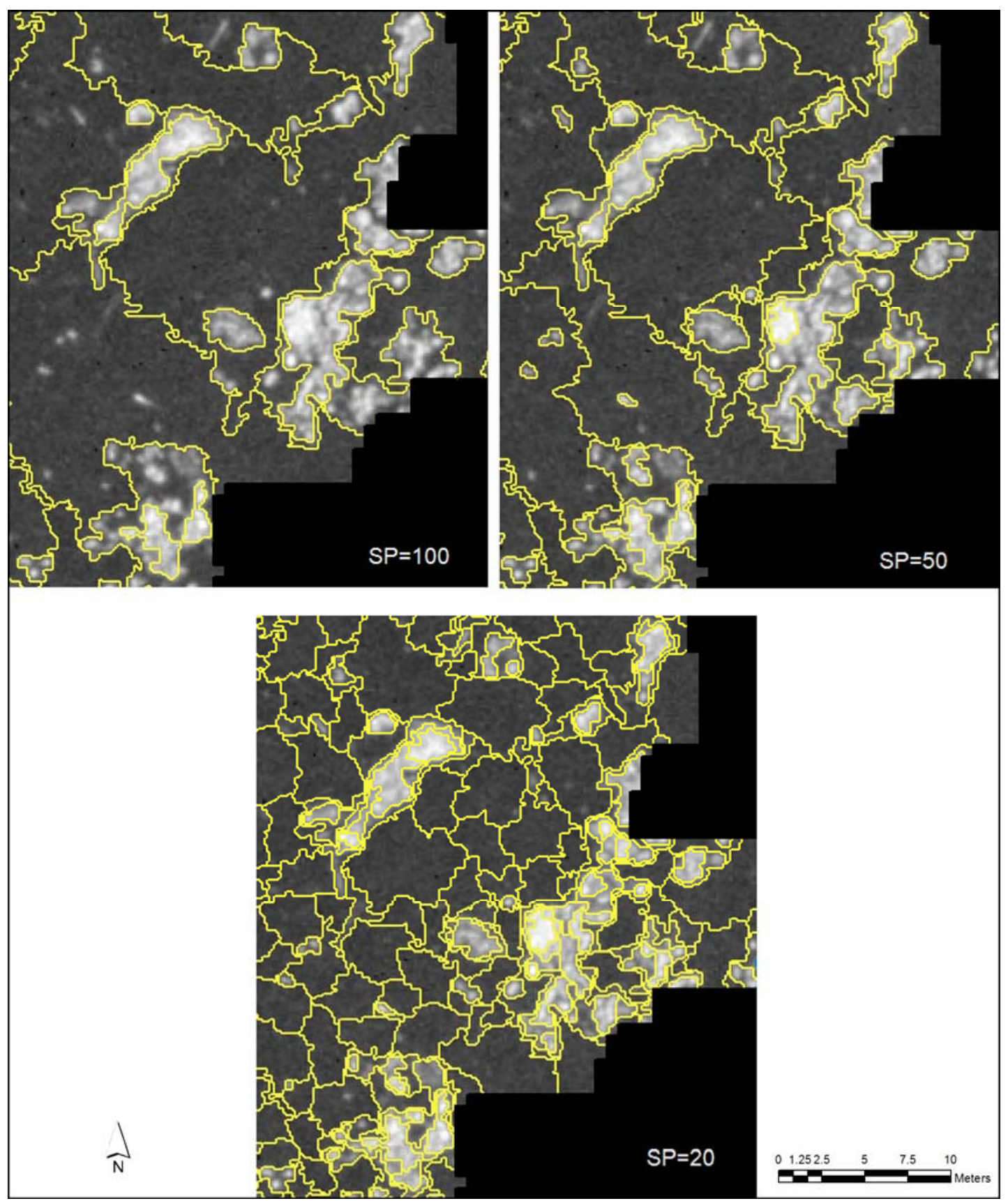

In classification of the segments, it was found that brightness generally varied between water (darkest), logs (moderate), and vegetation (brightest) but that their histograms overlapped significantly. Consequently, texture, shape and size were used in addition to brightness to classify these features. 
Through interactive histogram and image analysis segments with mean brightness greater than a selected threshold were classified as wetland vegetation and logs while segments darker than this threshold were classified as water. Three thresholds were required for different portions of the mosaic due to minor differences in photo exposure between flight lines. The thresholds were $90 \mathrm{DN}$ for a block of 24 photos, $85 \mathrm{DN}$ for a block of 8 photos and $80 \mathrm{DN}$ for the remaining block of 6 photos. Such iterative testing was simple and fast to implement using the Feature View tool as all objects meeting a given criterion could be temporarily highlighted, allowing iterative manipulation of these thresholds to determine which most effectively distinguished water from the other two classes.

The above process effectively separated water segments from segments that were either wetland vegetation or logs. To separate logs from vegetation, because segmented log length (average $=6.2 \mathrm{~m}$; standard deviation $=3.4 \mathrm{~m}$ ) was much greater than log width, segments with a length to width ratio greater than 2.75 were classified as $\log$. In addition, log segments satisfying this criterion that were longer than $50 \mathrm{~m}$ were removed (assigned to the Other class) as, geometrically, they were unlikely to be logs or wetland vegetation but were residual parts of linear features outside wetlands (e.g., road edges, the power-line corridor). Of the remaining log segments, those that were larger than $500 \mathrm{~m}^{2}$ in area were re-classified as wetland vegetation, as the extensive fieldwork and air photo interpretation, did not identify any log clumps larger than this.

\subsection{Classification Accuracy Assessment}

The map of wetlands and within wetland habitat features was assessed for classification accuracy using random sampling. Field data and objects visually interpreted from the orthophotos served as the reference data. For wetland accuracy assessment, a sample of 50 wetlands was desired to be representative of the approximately 700 wetlands in the study area (see Section 4.1). To achieve this, random points were generated until they occurred in 50 wetlands. The total sample was 521 points, with 66 in wetlands (some wetlands had more than one point) and 455 in the Other class. A point was deemed to be in wetland if it fell within $20 \mathrm{~m}$ of a reference wetland, as the shore and near shore area of each wetland was generally comprised of wetland vegetation and considered to be suitable habitat. These reference data were tabulated against the Wetland/Other map in a $2 \times 2$ error matrix.

To determine the classification accuracy of within wetland habitat features, five random points were placed within each of the 50 wetlands selected above and each point was visually interpreted on the orthophoto to determine if it was water, wetland vegetation or log. However, since water was the dominant class by area within the wetlands, it was selected much more often than wetland vegetation or logs. Therefore, in each wetland where they existed, two visually interpreted logs and two wetland vegetation points were manually selected in the orthophotos without reference to the classification. Through this process, all wetlands had some wetland vegetation that was sampled for validation, while nine of the 50 sample wetlands did not have logs present. In assessing the class of the thematic map, sample points were deemed to be classified as wetland vegetation or water if the point and the area immediately surrounding the point (in about a $1 \mathrm{~m}$ or 2-3 pixel radius) was classified as these classes, respectively. Sample reference logs were deemed to be correctly classified if at least half their area was classified as log. These reference data were tabulated against the classified map in an error matrix. 


\subsection{Potential Habitat Mapping}

The classification results for the four primary habitat attributes (wetlands; within wetland water, vegetation and $\operatorname{logs}$ ) were combined to produce a potential habitat map. There are many ways to combine habitat attributes in such mapping (e.g., $[3,64,65]$ ) so the map presented is just one example of the type of product that could be derived from data types and methods similar to those of this study.

A subjective linear additive scoring system was defined as follows (Table 1). First, ponds with only open water and no logs or vegetation were given a score of 2 as they represent better habitat than the non wetland (Other) class. Next, wetland size was divided into four categories, wetland vegetation cover into five categories, and the number of logs per wetland into three categories. Scores for vegetation presence and abundance were varied based on wetland size. Lower scores were assigned to medium and large wetlands with low per cent vegetation cover as they are not as good habitat (provide less protection) as smaller wetlands with low vegetation cover. Also, small wetlands with very high vegetation cover and little open water were not deemed to be better habitat than similar sized wetlands with moderate vegetation, i.e., beyond a certain per cent cover suitability does not increase.

Table 1. Scoring system used as an illustrative example of potential Blanding's turtle habitat mapping from the habitat attributes wetlands (including open water), and within wetland vegetation and logs. The highest score of 10 would be obtained for a wetland $($ score $=2$ not shown in the table) with medium vegetation cover $($ score $=5)$ and $1-5$ or $>5$ $\operatorname{logs}$ if the wetland is small, or $>5 \operatorname{logs}$ if the wetland is medium or large in size (score $=3$ ).

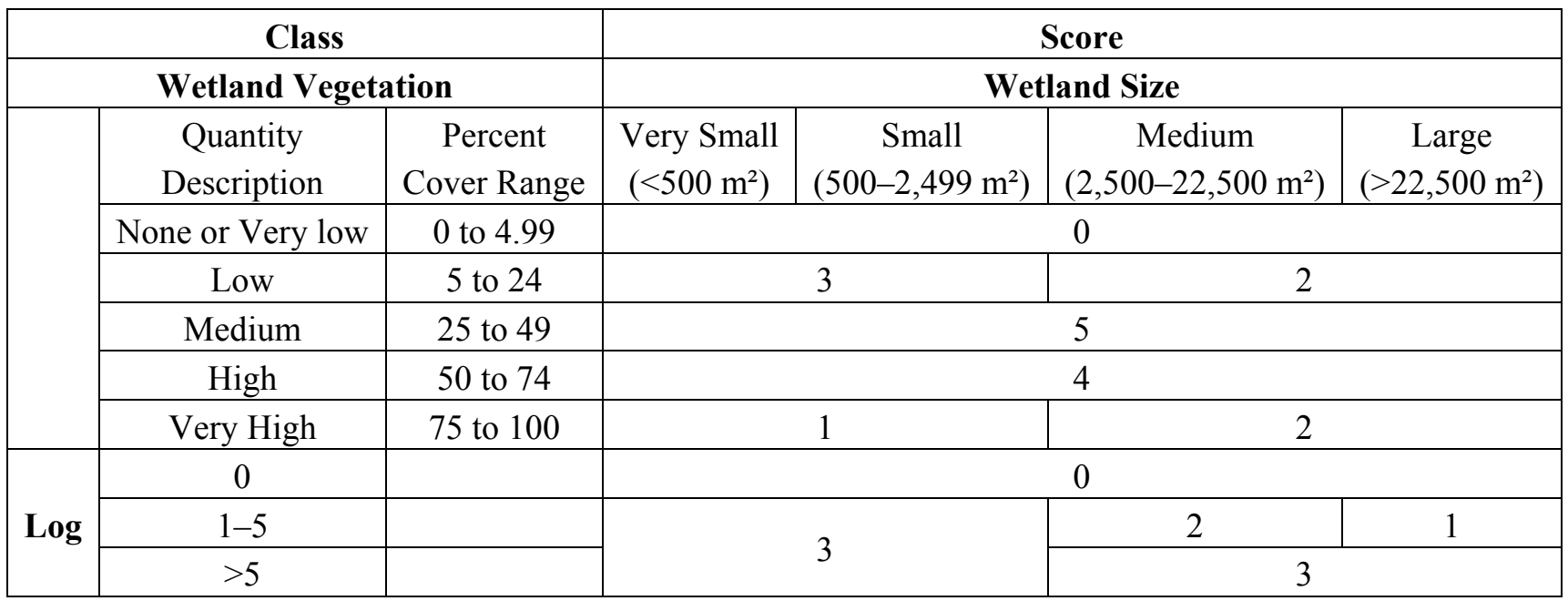

Some scores were consistent across wetland sizes (e.g., medium-high vegetation cover), because for any wetland size, this proportion of vegetation cover should provide adequate habitat resources. Finally, scores for log presence and abundance were varied based on wetland size. The number of logs also reaches a threshold of maximum suitability (i.e., the relationship is asymptotic). For example, in a small wetland, a couple of logs are sufficient as optimal habitat [50]. In a larger wetland, the threshold is slightly higher so the maximum was set at five. The potential habitat score for each wetland was calculated by summing the scores for wetland vegetation and logs together and adding the two base points for being a wetland. Using this scoring system, non wetlands have a score of zero and a wetland 
could potentially have a score of two to ten. The scores were then grouped into classes from unsuitable to very high suitability for map display and analysis (Table 2).

Validation of the habitat suitability map was conducted through frequency analysis of the recorded observation locations of Blanding's turtles (1996-2011) [18,43,44,46] against the suitability class of the most proximal wetland. It was not possible to conduct validation independently and rigorously using random sampling because of the spatial clustering of the observations, mostly near an easily accessed road crossing the park within the purple rectangle in Figure 4. Also, there were many wetlands within the study area without observations that could be suitable habitat, i.e., no observations at a wetland rated as good potential habitat does not mean the habitat score is wrong. For the 74 existing single point observations within the study area, only ten were farther than $250 \mathrm{~m}$ from a wetland. Of these, seven were on or beside roads and two were in bays of the large lake within the study area. The remaining 65 observations were combined with the 2009-2011 telemetry data. In the telemetry data, turtles were associated with the closest wetland given there was one within $250 \mathrm{~m}$, and given multiple telemetry location points for a single turtle, only one wetland was used as an observation.

Table 2. Potential habitat levels assigned to the resulting habitat scores.

\begin{tabular}{cc} 
Habitat Suitability Score & Habitat Suitability Level \\
\hline $2-3$ & Unsuitable \\
4 & Low \\
$5-6$ & Medium \\
$7-8$ & High \\
$9-10$ & Very High \\
\hline
\end{tabular}

\section{Results}

\subsection{Wetland and Within Wetland Habitat Attribute Classification}

Wetland mapping identified 693 wetlands in the study area. From all known sources (as described earlier), only 383 wetlands and open water bodies had been previously mapped. The high-resolution orthophotos and the processing methods used in this research were able to identify wetlands/water bodies that were probably smaller than the minimum mapping unit or resolution of previous mapping efforts. Of the 693 classified wetlands, 133 were smaller than $100 \mathrm{~m}^{2}$. These were removed from further analysis because they were difficult to reliably interpret in the photos so validation was not possible. They were also below the commonly reported minimum wetland sizes for Blanding's turtles (e.g., average 0.18 ha [12]; 1-1.5 ha [26]). Of the classified wetlands, $82 \%$ had wetland vegetation (5\%-50\% cover) and $90 \%$ had $\log (\mathrm{s})$ present, with 59\% having more than five logs.

Figure 8 [66] shows an example wetland in the imagery and as its classification for habitat features. The accuracy assessment for wetlands (Table 3) showed very low error. Seven of the 66 wetland reference points were misclassified as the Other class and seven of the 455 Other sample points were misclassified as wetland. The error matrix for the within wetland habitat attributes (Table 4) also shows very high accuracies for all classes. 
Figure 8. Orthophoto of a wetland (from the wetland mask) and the resulting classification of three Blanding's turtle habitat attributes: water, wetland vegetation, and logs [66].
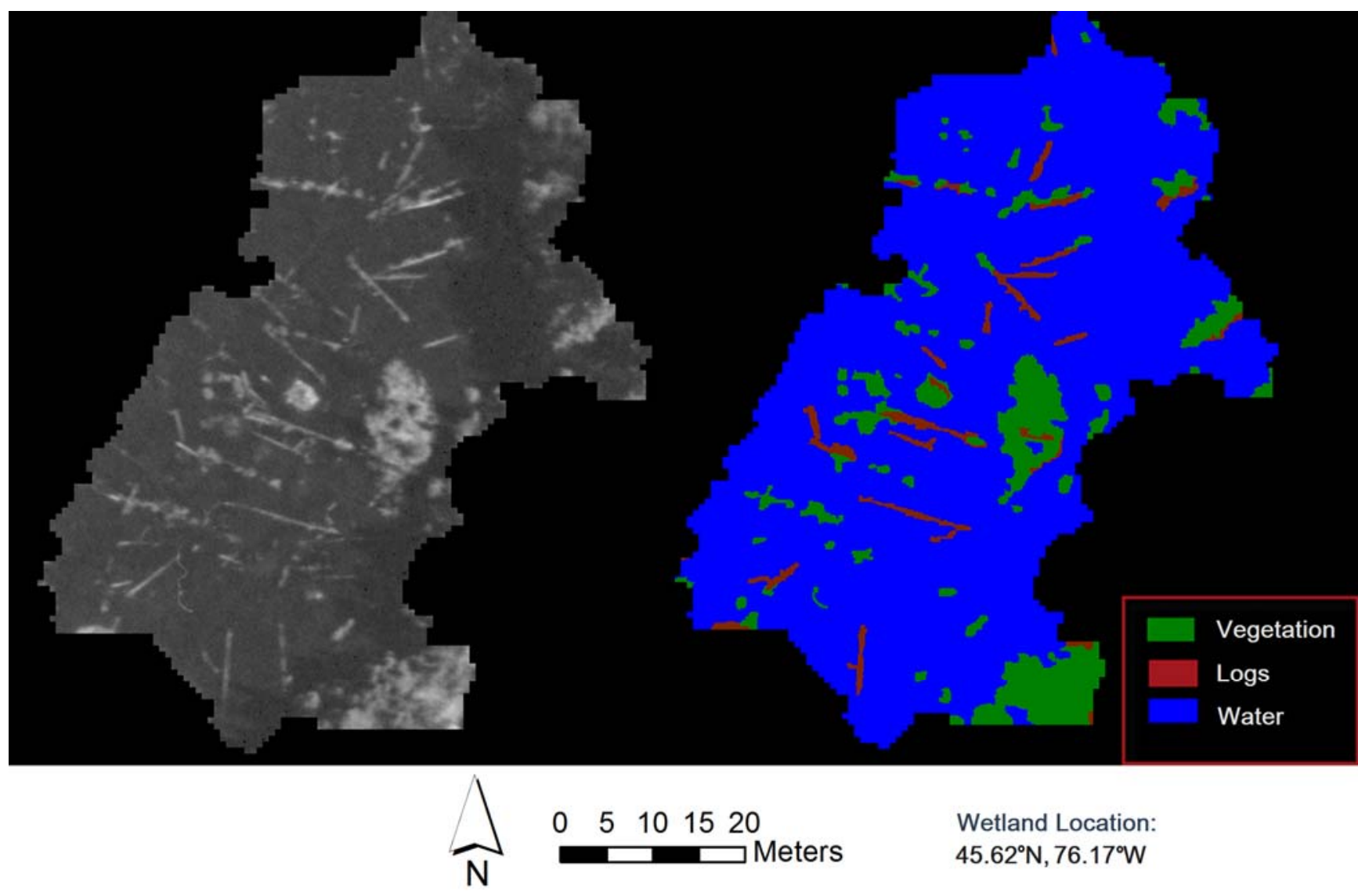

Table 3. Error matrix for wetland classification.

\begin{tabular}{ccccc}
\hline \multirow{2}{*}{ Classification } & \multicolumn{3}{c}{ Reference Interpretation } & \multirow{2}{*}{ User's Accuracy (\%) } \\
& Wetland & Other & Total & 89.4 \\
Wetland & 59 & 7 & 66 & 98.5 \\
Other & 7 & 448 & 455 & \\
Total & 66 & 455 & 521 & Overall Accuracy 97.5\% \\
\hline
\end{tabular}

Table 4. Error matrix for within wetland habitat feature classification.

\begin{tabular}{|c|c|c|c|c|c|}
\hline \multirow{2}{*}{ Classification } & \multicolumn{4}{|c|}{ Reference Interpretation } & \multirow{2}{*}{ User's Accuracy (\%) } \\
\hline & Water & Wetland Vegetation & $\log$ & Total & \\
\hline Water & 200 & 6 & 1 & 207 & 96.6 \\
\hline Wetland Vegetation & 3 & 93 & 14 & 110 & 84.5 \\
\hline $\log$ & 0 & 1 & 66 & 67 & 98.5 \\
\hline Total & 203 & 100 & 81 & 384 & \\
\hline Producer's Accuracy (\%) & 98.5 & 93.0 & 81.5 & & Overall accuracy $93.5 \%$ \\
\hline
\end{tabular}

Interpretation of the orthophotos at the sample locations and at other locations revealed that classification error, although small, could be mainly attributed to a few sources. In creation of the wetland mask, continuous wetland vegetation along borders of wetlands, at ends of wetlands, or in 
narrow areas between two wetland sections, was not retained as much in the wetland class as water bodies with vegetation patches dispersed throughout. Continuous wetland vegetation with no surrounding water was often confused with forest floor leaf litter and therefore removed with deciduous forest during the processing. Removal of this continuous vegetation made some connected wetland sections appear spatially separated. These areas were very small in relation to the wetlands with open water that were mapped, but they could represent good habitat.

Within wetlands, shadows created by isolated trees and tree groups were rare but they were generally misclassified as water. Classified within wetland vegetation was in general agreement with the orthophotos and field survey data. Some logs that were visually evident as linear structures were misclassified as vegetation or water, particularly if they were submerged. This is evident in Figure 8, where all the logs visible in the photo are not classified as logs in the map. While this type of error affected the absolute number of logs detected, relative abundance in the habitat scoring system was not adversely impacted.

\subsection{Potential Habitat Mapping}

Figure 9 shows a portion of the potential habitat map using the generalized classes of Table 2. An unsuitable score (2-3) generally indicated a wetland with none or very low vegetation cover and no logs, or a wetland with very high vegetation cover, little open water, and no logs. Conversely, very highly suitable wetlands (9-10) had medium to high (25-75\%) vegetation cover and more than one log present. Intermediate scores represented various non-optimal combinations of these attributes. Based on these, the study area was found to have an abundance of potential habitat.

Table 4. Frequency distribution of existing Blanding's Turtle observations in the study area with respect to wetland habitat suitability score. Each observation was matched to the closest wetland within a $250 \mathrm{~m}$ radius.

\begin{tabular}{cc}
\hline Habitat Suitability Score & Number of Observations \\
\hline $2-3$ & 1 \\
4 & 0 \\
$5-6$ & 7 \\
$7-8$ & 72 \\
$9-10$ & 35 \\
\hline
\end{tabular}

Of the combined set of 115 single point and telemetry Blanding's turtle observations within $250 \mathrm{~m}$ of a wetland, six wetlands were mapped for the first time in this study. Table 4 presents the habitat suitability classes associated with these observations. The vast majority $(92.3 \%)$ of the observations were closest to a wetland of high or very high suitability. Six per cent of the observations were closest to wetlands of medium suitability while these wetlands represented $16.7 \%$ of the wetlands mapped and assessed in the study area. Only $1.7 \%$ were closest to wetlands with scores of 4 or less while these wetlands represented $4.9 \%$ of those mapped and assessed. Thus, despite the clustered nature of the existing observations, these results indicate a strong preference of Blanding's turtles for wetlands with a mix of open water, within wetland vegetation and logs that were classified as high and very high suitability. Of note is that twice as many observations were closest to wetlands with scores of 7 or 8 
versus 9 or 10, indicating (with reference to Table 1) that Blanding's turtles may prefer higher amounts of vegetation cover, in the 50-75\% range, rather than the medium amounts that were scored highest in Table 1, or that only one or a few logs are needed in larger wetlands for use in spring basking rather than 'more than 5', which was scored higher in Table 1.

Figure 9. Example of a portion of the Blanding's turtle habitat suitability map for the study area that was derived from an additive scoring system for wetlands, and the presence and abundance of wetland vegetation, and logs (Road source: [45]).

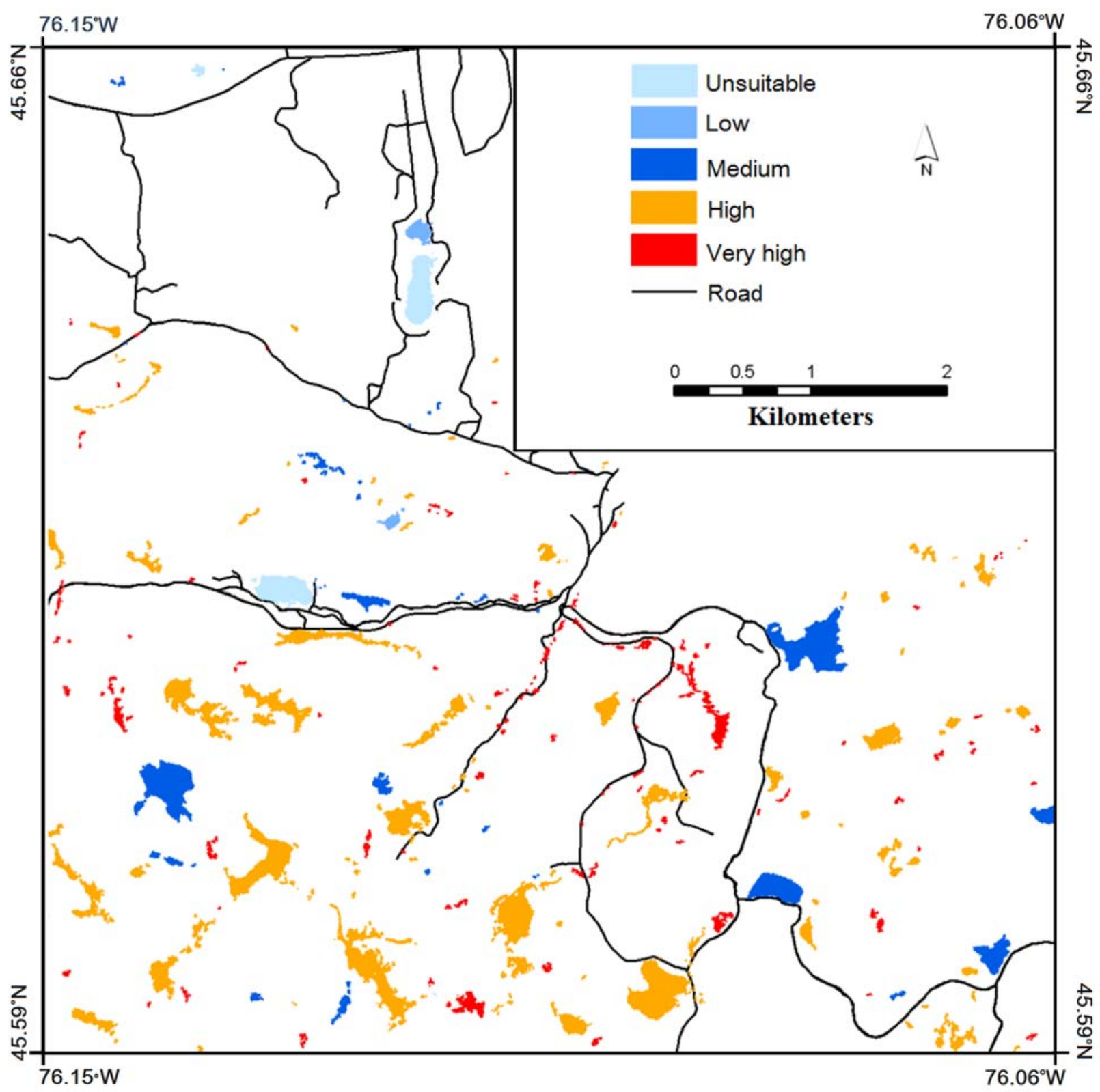

\section{Discussion}

Object-based segmentation and rule-based classification of high-resolution orthophotos using a combination of spectral, texture, shape and size information was very successful at mapping Blanding's turtle habitat. Two scales of mapping were conducted: a broader scale to discriminate potential wetlands from other land cover types, and a finer scale to map water, vegetation patches, and 
logs within wetlands. These are among the most important single indicators of habitat and life cycle activities of the Blanding's turtle [10,11,13,14,21]

At the broader wetland scale, many previously unmapped wetlands were detected and delineated. Figure 10 shows an example of such a wetland, that had a high potential habitat score, and at which a Blanding's turtle was observed by the authors. In comparison to the literature, wetland mapping has been conducted at diverse scales using many sensor types and classification methods. Many studies report high accuracies similar to the current study although the minimum wetland size that can be accurately classified is scale dependent. For example, similar accuracies were achieved using MLC of Landsat ETM+ imagery to classify a pond and marsh wetland class [67], and using fusion of radar and Landsat ETM+ data [68] but for wetland sizes much larger than many of those classified in this study (e.g., minimum wetland size about 3,600 $\mathrm{m}^{2}$ [67]). Dingle Robertson and King [60], although reporting lower accuracies, found object based wetlands classification using eCognition and Landsat 5 TM data to be significantly better than MLC pixel based classification in both single date and temporal land cover change analysis. At a finer scale, high wetland mapping accuracy was achieved with $4 \mathrm{~m}$ pixel hyperspectral imagery [69]. By combining a $1 \mathrm{~m}$ LiDAR DEM with fused IKONOS Panchromatic ( $1 \mathrm{~m}$ pixels) and Multispectral (4 m pixels) imagery, Maxa and Bolstad [70], were able to map five distinct wetland types. Thus, as spatial resolution of the imagery increases, the minimum wetland size and attribute detail that can be accurately mapped decreases and increases, respectively. In the current study, the minimum wetland size retained was $100 \mathrm{~m}^{2}$, which represented 500 pixels. While wetlands of this size might have been detectable with high-resolution satellite imagery, the same accuracy of within wetland habitat feature classification would be unlikely.

The accurate mapping of within wetland vegetation and logs can aid the field sampling design of future inventories as many observations of Blanding's turtle are made in spring when it is often seen on either one of these two features. The object based approach was capable of producing more homogeneous class extents than would be expected for pixel-based classification. For example, in the case of wetland vegetation, brightness variability would result in a speckled pixel-based map, whereas segmentation and classification produced a single class assignment for each vegetation patch.

It is also surmised that logs were more effectively mapped using the object-based approach. The use of length: width as a discriminator of logs, which were spectrally similar to forest leaf litter and some senescent wetland vegetation, required segmented objects. In comparison to the literature, as above, many studies have been conducted at coarser scales than the current study, and all for within wetland water and vegetation types; no studies have been found that detect and map deadwood within wetlands as a significant habitat feature. For example, Dillabaugh et al. [34] and Dechka et al. [71] used brightness and texture of $4 \mathrm{~m}$ pixel IKONOS imagery to classify within wetland vegetation communities with high accuracy. Gilmore et al. [72] utilized LiDAR and multi-temporal Quickbird imagery with an object-oriented classification approach to classify three marsh vegetation species. Dogan et al. [73] and Yuan and Zhang [74] used $2.8 \mathrm{~m}$ pixel QuickBird imagery to classify submerged plants within wetlands. Thus, overall the accuracies achieved in this study for classification of within wetland vegetation and open water compare to other studies but, as stated above, the minimum mapping unit of this study is generally much smaller, providing capability to detect and map smaller patches of these features as well as logs that could not be achieved with high-resolution satellite imagery. 
The presence and abundance of these habitat features were used to construct and map a potential habitat scoring system. As noted earlier, habitat suitability mapping is a large and diverse field with many sophisticated methods proposed in the literature (e.g., [75-77]). The simple method used provided a very strong representation of potential habitat distribution in the study area and was a significant improvement over what was previously available. It can be used to aid targeting of future inventories and other studies related to conservation management. For example, the connectivity between wetlands, which is critical to the Blanding's turtle [12], could be analyzed by integrating the map produced here with topography and the telemetry data collected for some turtles in 2009-2011 to define areas of multiple wetlands that together provide strong habitat potential.

Figure 10. An example wetland, 0.15 ha in area, that was not classified before this research that has had Blanding's turtle observations. Orthophoto (upper left), classified habitat features (upper right), a Blanding's turtle observed in May 2009 (bottom).

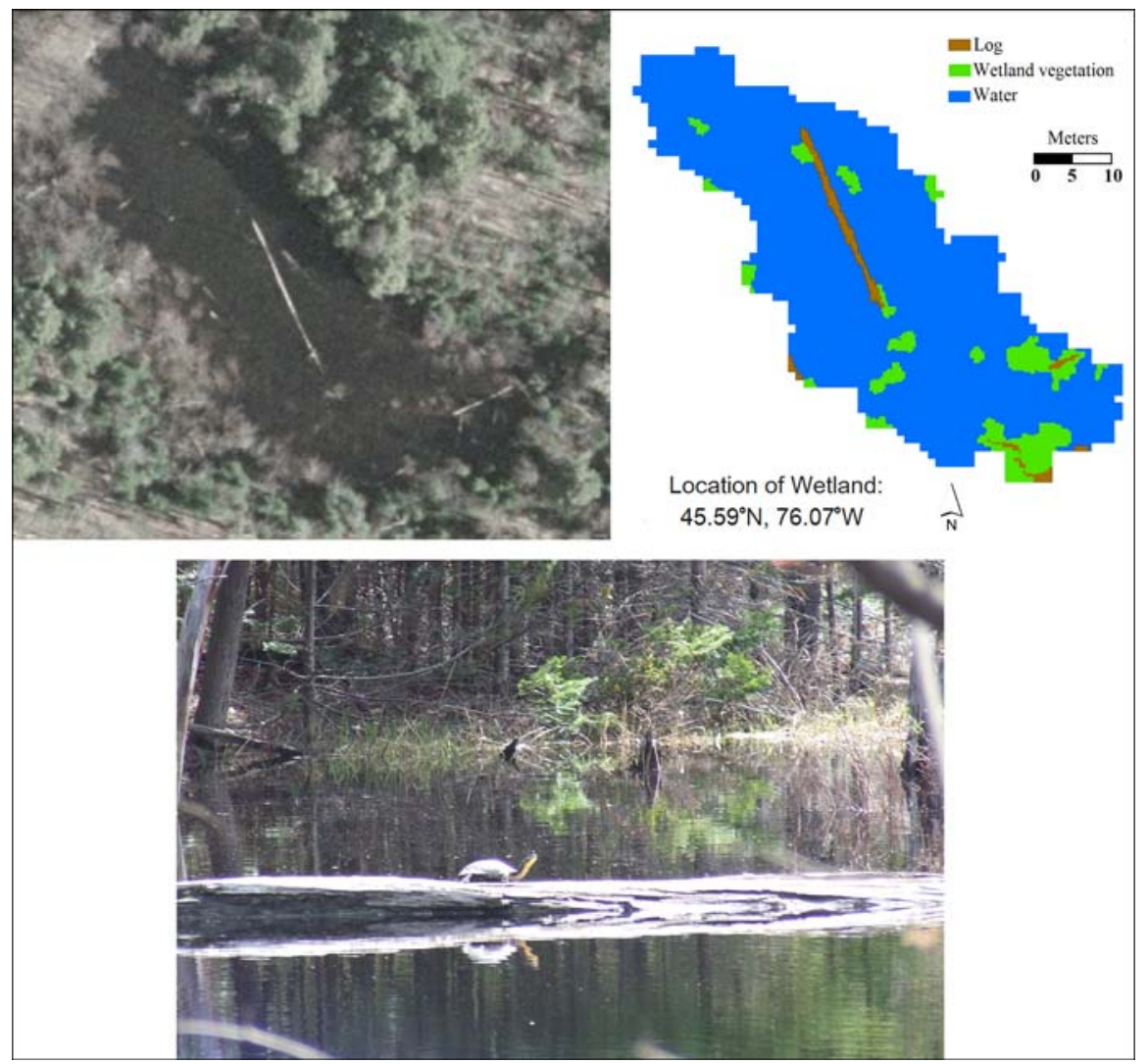

This research focused on four habitat attributes that had distinct potential for mapping using existing leaf-off high resolution color orthophotos and that are key providers of food, protection, thermal regulation, hibernation, etc., for the Blanding's turtle. Other habitat types such as vernal pools beneath forest canopies that are often used in transit across upland areas were not included because they were deemed to have lower potential for detection using remotely sensed imagery. The primary limitation of the orthophotos was their poor spectral information content as the three spectral bands had wide and overlapping bandwidths. Also, in spring most vegetation was senescent and spectrally similar to forest leaf litter and tree trunks. Summer imagery of more narrow bandwidths and including a near infrared band would aid in vegetation discrimination, provided the wetland vegetation was not 
overtopped by tree canopies, which was found to be problematic in this study area as stated in Section 3.2. In image processing, to accurately assign segmented objects to the correct class, iterative testing was required to develop the optimal sequential rule-base. This rule-base is site specific; for a different area, image scale, or time of year (sun angle-view angle differences), it would have to be modified. However, the iterative and interactive method in general was found to be fast and easy to implement, and validation was efficient due to the very high spatial resolution of the photos so this is not viewed as a significant limitation.

An alternative approach would be to input training data into a classifier such as a classification and regression tree (CART) (e.g., [78,79]) to attempt to automatically find optimal rules and data thresholds for classification of wetlands and the within wetland habitat features. A more automated approach such as this was not conducted in this study because it was felt the multiple decision points, data types (brightness, texture, shape and size) and thresholds that were needed to first classify the features and then to refine the classifications would result in very complex and unwieldy sets of rules in a decision tree.

\section{Conclusions}

Using leaf-off $20 \mathrm{~cm}$ pixel orthophotos and object-based segmentation and classification, habitat critical to the threatened Blanding's turtle was mapped. Two scales of analysis were implemented: (1) at a coarse scale (object segmentation scale parameter of 300) to delineate and classify whole wetlands, and (2) at a finer scale (segmentation scale parameter of 20) to delineate and classify within wetland habitat features of water, vegetation and logs. High accuracies were achieved at both scales. At the coarse scale, wetland classification accuracy was $89.4 \%$ and, at the finer scale, accuracy of the within wetland features varied between $81.5 \%$ and $98.5 \%$. The number of mapped wetlands in the study area almost doubled, as 310 new wetlands were identified, most being smaller than the minimum mapping unit of previous mapping efforts. Six new wetlands were mapped that also had recorded Blanding's turtle observations. A map combining the selected wetland and within wetland attributes showed the spatial distribution of potential habitat throughout the study area. Of the 115 existing Blanding's turtle observations, $92.3 \%$ were closest to a wetland of high or very high suitability. These results are being used in further field inventory planning and in combination with other data such as turtle movement obtained through telemetry to advance understanding of how the Blanding's turtle selects and utilizes habitat. Future research will include validation of Blanding's turtle habitat preferences and movement in relation to the mapped wetlands as well as evaluation of spatial extension of the rule base to the other main habitat area near the Ottawa River.

\section{Acknowledgments}

This research was funded by an NSERC Discovery grant to D. King. Field support was provided by the Carleton University Geomatics and Landscape Ecology Research Laboratory through the Canada Foundation for Innovation and other funding. The National Capital Commission provided access to the Gatineau Park aerial orthophotos and other support that was vital to this research. Blanding's turtle observation and telemetry data were provided by the following: (1) Ministère des Ressources naturelles et de la Faune, Québec, Direction de l'aménagement de la faune de l'Outaouais); 
(2) Conservation de la Nature Canada (2008 data); (3) Atlas des Amphibiens et Reptiles du Québec, (4) National Capital Commission, Ottawa, Canada. We are very grateful to Yohann Dubois of the Ministère des Ressources naturelles et de la Faune, Québec for scientific advice on the Blanding's turtle, field inventory methods and existing data. Gabrièle Fortin, MSc candidate in Biology at the University of Ottawa kindly provided GIS shapefiles for some of the observations and telemetry data. The field assistance of Valerie Torontow and scientific advice of Scott Mitchell (Geography, Carleton University) are greatly appreciated.

\section{References}

1. Gibbons, J.W.; Scott, D.E.; Ryan, T.L.; Buhlmann, K.A.; Tuberville, T.D.; Metts, B.S.; Green, J.L.; Mills, T.; Leiden, Y.; Poppy, S.; Winne, C.T. The global decline of reptiles, Déjà vu Amphibians. Bioscience 2000, 50, 653-666.

2. McDermid, G.; Franklin, S.; LeDrew, E. Remote sensing for large-area habitat mapping. Prog. Phys. Geog. 2005, 29, 449-474.

3. Store, R.; Kangas, J. Integrating spatial multi-criteria evaluation and expert knowledge for GIS-based habitat suitability modelling. Landscape Urban Plan. 2001, 55, 79-93.

4. Pasher, J.; King, D.; Lindsay, K. Modelling and mapping potential hooded warbler (Wilsonia citrina) habitat using remotely sensed imagery. Remote Sens. Environ. 2007, 107, 471-483.

5. Giguère, S. Digital Photograph; Canadian Wildlife Service, Environment Canada: Quebec, QC, Canada, 2008.

6. Committee on the Status of Endangered Wildlife in Canada (COSEWIC). COSEWIC Assessment and Update Status Report on the Blanding's Turtle (Emydoidea blandingii) Canada: Nova Scotia Population, Great Lakes/St. Lawrence Population; Environment Canada: Ottawa, ON, Canada, 2005; p. 40.

7. Blanding's Turtle Recovery Team. Nova Scotia's Blanding's Turtles Conservation and Recovery; Blanding's Turtle Recovery Team: Wolfville, NS, Canada, 2006. Available online: http://www.speciesatrisk.ca/blandings/about.htm (accessed on 29 September 2011).

8. Natural Heritage and Endangered Species Program. Massachusetts Forestry Conservation Management Practices for Blanding's Turtles; Natural Heritage and Endangered Species Program Massachusetts Division of Fisheries and Wildlife: Westborough, MA, USA, 2007.

9. Edge, C.B.; Steinberg, B.D.; Brooks, R.J.; Litzgus, D.L. Habitat selection by Blanding's turtles (Emydoidea blandingii) in a relatively pristine landscape. Ecoscience 2010, 17, 90-99.

10. Pappas, M.J.; Brecke, B.J. Habitat selection of juvenile Blanding's turtles, Emydoidea blandingii. J. Herpetol. 1992, 26, 233-234.

11. Ross, D.A.; Anderson, R.K. Habitat use, movements, and nesting of Emydoidea blandingii in Central Wisconsin. J. Herpetol. 1990, 24, 6-12.

12. Joyal, L.; McCollough, M.; Hunter, M., Jr. Landscape ecology approaches to wetland species conservation: A case study of two turtle species in southern Maine. Conserv. Biol. 2001, 15, 1755-1762.

13. Rowe, J.; Moll, E. Radiotelemetric study of activity and movements of the Blanding's turtle (Emydoidea blandingii) in Northeastern Illinois. J. Herpetol. 1991, 25, 178-185. 
14. Millar, C.S.; Blouin-Demers, G. Spatial ecology and seasonal activity of Blanding's turtles (Emydoidea blandingii) in Ontario, Canada. J. Herpetol. 2011, 45, 370-378.

15. Kofron, C.P.; Schreiber, A.A. Ecology of two endangered aquatic turtles in Missouri: Kinosternon flavescens and Emydoidea blandingii. J. Herpetol. 1985, 19, 27-40.

16. Bury, R.; Germano, D. Differences in habitat use by Blanding's turtles, Emydoidea blandingii, and Painted turtles, Chysemys picta, in the Nebraska sandhills. Am. Midl. Nat. 2003, 149, 241-244.

17. Hamernick, M.G. Home Ranges and Habitat Selection of Blanding's Turtles (Emydoidea blandingii) at the Weaver Dunes, Minnesota; Nongame Wildlife Program Final Report; Minnesota Department of Natural Resources: St. Paul, MN, USA, 2000; p. 18. Available online: http://www.dnr.state.mn.us/eco/nongame/projects/research_reports/abstracts/reptiles/hamernick20 00.html (accessed on 29 September 2011)

18. Commission de la capitale nationale. Projet d'inventaire de la Tortue mouchetée (Emydoidea blandingii) au parc de la Gatineau; Environnement, terrains et parcs de la capital: Chelsea, QC, Canada. 2007; p. 11.

19. Power, T.D.; Herman. T.; Kerekes, J. Water colour as a predictor of local distribution of Blanding's turtles, Emydoidea blandingii, in Nova Scotia. Can. Field-Nat. 1994, 108, 17-21.

20. Grgurovic, M.; Sievert, P. Movement patterns of Blanding's turtles (Emydoidea blandingii) in the suburban landscape of eastern Massachusetts. Urban Ecosyst. 2005, 8, 203-213.

21. Bourque, G. Investigating Variables Affecting Blanding's Turtle (Emydoidea blandingii) Patch Occupancy and Trapping Success in Nova Scotia. Master's Thesis, Biology Department, Acadia University, Wolfville, NS, Canada, 2006; p. 79.

22. Innes, R.J.; Babbitt, K.J.; Kanter, J.J. Home range and movement of Blanding's turtles (Emydoidea blandingii) in New Hampshire. Northeast. Nat. 2008, 15, 431-444.

23. Carroll, D.M.; Ultsch, G.R. Emergence season and survival in the nest of hatchling turtles in southcentral New Hampshire. Northeast. Nat. 2007, 14, 307-310.

24. Piepgras, S.A.; Lang, J.W. Spatial ecology of Blanding's turtle in central Minnesota. Chelonian Conserv. Bi. 2000, 3, 589-601.

25. St-Hilaire, D. Rapport sur la situation de la tortue mouchetee (Emydoidea blandingii) au Québec; Société de la faune et des parcs du Québec, Direction de l'aménagement de la faune de l'Outaouais: Outaouais, QC, Canada, 2003; p. 27.

26. Attum, O.; Lee, Y.; Roe, J.; Kingsbury, B. Wetland complexes and upland-wetland linkages: Landscape effects on the distribution of rare and common wetland reptiles. J. Zool. 2008, 275, 245-254.

27. Ontario Ministry of Natural Resources. Wetland Restoration; 2008. Available online: http://www.mnr.gov.on.ca/en/Business/Biodiversity/2ColumnSubPage/STEL02_176753.html (accessed on 29 September 2011).

28. Congdon, J.D.; Nagle, R.D.; Kinney, O.M.; Osentoski, M.; Avery, H.W.; van Loben Sels, R.C.; Tinkle, D.W. Nesting ecology and embryo mortality: Implications for hatchling success and demography of Blanding's turtles (Emydoidea blandingii). Chelonian Conserv. Bi. 2000, 3, 569-579. 
29. Congdon, J.; Dunham, A.; van LobenSels, R. Delayed sexual maturity and demographics of Blanding's Turtles (Emydoidea blandingii): Implications for conservation and management of long-lived organisms. Conserv. Biol. 1993, 7, 826-833.

30. Murphy, P.N.; Ogilvie, J.; Connor, K.; Paul, A.A. Mapping wetlands: A comparison of two different approaches for New Brunswick, Canada. Wetlands 2007, 27, 846-854.

31. Meter, R.V.; Bailey, L.L.; Campbell Grant, E.H. Methods for estimating the amount of vernal pool habitat in the northeastern United States. Wetlands 2008, 28, 585-593.

32. Larthrop, R.G.; Montesano, P.; Tesauro, J.; Zarate, B. Statewide mapping and assessment of vernal pools: A New Jersey case study. J. Environ. Manage. 2005, 76, 230-238.

33. Becker, B.L.; Lusch, D.P.; Qi, J. A classification-based assessment of the optimal spectral and spatial resolutions for Great Lakes coastal wetland imagery. Remote Sens. Environ. 2007, 108, 111-120.

34. Dillabaugh, K.A.; King. D.J. Riparian marshland composition and biomass mapping using IKONOS imagery. Can. J. Remote Sens. 2008, 34, 143-158.

35. Touzi, R.; Deschamps, A.; Rother, G. Wetland characterization using polarimetric RADARSAT-2 capability. Can. J. Remote Sens. 2007, 33, S56-S67.

36. Pietroniro, A.; Leconte. R. A review of Canadian remote sensing applications in hydrology. Hydrol. Process. 2000, 14, 1641-1666.

37. Kushwaha, S.P.; Dwivedi. R.S.; Rao, B.R. Evaluation of various digital image processing techniques for detection of coastal wetlands using ERS-1 SAR data. Int. J. Remote Sens. 2000, 21, 565-579.

38. Beaudry, F.; deMaynadier, P.G.; Hunter, M.L., Jr. Seasonal dynamic habitat use by spotted (Clemmys guttata) and Blanding's turtles (Emydoidea blandingii) in Maine. J. Herpetol. 2009, 43, 636-645.

39. NCC. Digital Aerial Orthophotos of Gatineau Park; National Capital Commission: Quebec, QC, Canada, 2007; Computer file.

40. Natural Resources Canada (NRCan). National Topographic Database: Quebec Boundary; 2007. Available online: http://www.library.carleton.ca/gis/ntdb.htm (accessed on 29 September 2011).

41. Google Maps. Gatineau Park; 2009. Available online: http://maps.google.ca/maps?hl=en\&tab=wl (accessed on 29 September 2011).

42. The National Capital Commission. Gatineau Park, Natural Resources. Government of Canada, 2005. Available online: http://www.ncc-ccn.ca/bins/ncc_web_content_page.asp?cid=1629716299-10170-49899-50069\&lang=1 (accessed on 29 September 2011).

43. Dubois, Y. Distribution de la tortue mouchetée (Emydoidea blandingii) et cartographie des aires prioritaires de conservation et des corridors écologiques à l'intérieur et en périphérie du parc de la Gatineau; Conservation de la nature Canada, pour la Commission de la capitale nationale 2009; p. 56.

44. St-Hilaire, D.; Caron, J.; Dubois, Y. Captures, caractéristiques biologiques, déplacements, et sites fréquentés par la tortue mouchetée (Emydoidea blandingii) au sud de l'Outaouais de 1996 à 1999; Ministère des Ressources naturelles et de la Faune, Québec, Direction de l'aménagement de la faune de l'Outaouais: Outaouais, QC, Canada, 2008; p. 56. 
45. Natural Resources Canada (NRCan). National Topographic Database: Region Quyon; 2007. Available online: http://www.library.carleton.ca/gis/ntdb.htm (accessed on 29 September 2011).

46. Atlas of Amphibians and Reptiles of Quebec; Quebec, Canada, 2009. Available online: http://www.atlasamphibiensreptiles.qc.ca/ (accessed on 29 September 2011).

47. Ducks Unlimited Canada. Liste des données existantes sur les milieux humides utilisées pour générer les Plans régionaux de conservation des milieux humides de CIC (PRCMH); 2008. Available online: http://www.ducks.ca/fr/province/qc/outils/pdf/donnees_prcmh_sources_ mars2009.pdf (accessed on 29 September 2011).

48. Québec Ministère des Ressources naturelles et de la Faune (QMRNF) 2008. Base de données topographiques du Québec (BDTQ), 1999; 1:20,000.

49. Belanger, L.; Grenier, M. Conservation Atlas of Wetlands; Environment Canada and the Canadian Wildlife Service: Quebec, QC, Canada, 2003.

50. Dubois, Y. Personal communication. July 2009.

51. Hartwig, T.S.; Kiviat, E. Microhabitat Association of Blanding's Turtles in Natural and Constructed Wetlands in Southeastern New York. J. Wildlife Manage. 2007, 7, 576-582.

52. Garmin Ltd. eTrex Owner's Manual; Garmin Ltd.: Olathe, KS, USA, 2007. Available online: http://static.garmincdn.com/pumac/eTrexH_OwnersManual.pdf (accessed on 29 September 2011).

53. Pasher, J.; King, D.J. Multivariate forest structure modelling and mapping using high resolution airborne imagery and topographic information. Remote Sens. Environ. 2010, 114, 1718-1732.

54. Lillesand, T.; Kiefer, R.; Chipman, J. Remote Sensing and Image Interpretation, 6th ed.; John Wiley \& Sons: Toronto, ON, Canada, 2008; p. 89.

55. Burnett, C.; Blaschke, T. A multi-scale segmentation/object relationship modeling methodology for landscape analysis. Ecol. Model. 2003, 168, 233-249.

56. Fournier. R.; Grenier. M.; André. L.; Robert. H. Towards a strategy to implement the Canadian Wetland inventory using satellite remote sensing. Can. J. Remote Sens. 2007, 33, Suppl 1, s1-s16.

57. Grenier, M.; Demers, A.; Labrecque, S.; Benoit, M.; Fournier, R.A.; Drolet, B. An object-based method to map wetland using RADARSAT-1 and Landsat ETM images: Test case on two sites in Quebec, Canada. Can. J. Remote Sens. 2007, 33, Suppl. 1, 28-45.

58. Lucieer, V.L. Object-oriented classification of sidescan sonar data for mapping benthic marine habitats. Int. J. Remote Sens. 2008, 29, 905-921.

59. Definiens AG. Definiens Developer User Guide; Definiens AG: Munich, Germany, 2007.

60. Dingle Robertson, L.; King, D.J. Comparison of pixel- and object-based classification in land cover change mapping. Int. J. Remote Sens. 2011, 32, 1505-1529.

61. Bock, M.; Xofis, P.; Mitchley, J.; Rossner, G.; Wissen, M. Object-oriented methods for habitat mapping at multiple scales - Case studies from Northern Germany and Wye Downs, UK. J. Nat. Conserv. 2005, 13, 75-89.

62. Varela Diaz, R.A.; Rego, R.P.; Igleseas, C.S.; Sobrino, M.C. Automatic habitat classification methods based on satellite images: A practical assessment in the NW Iberia coastal mountains. Environ. Monit. Assess. 2008, 144, 229-250.

63. Haralick, R.M. Statistical and structural approaches to texture. Proc. IEEE 1979, 67, 786-804. 
64. Catarina, V.; Fonseca, V.; Cabral, H.; Costa, M.J. Habitat suitability index models for the juvenile soles, Solea solea and Solea senegalensis, in the Tagus estuary: Defining variables for species management. Fish. Res. 2006, 82, 140-149.

65. Larson, M.; Thompson, F., III; Millspaugh, J.; Dijak, W.; Shifley, S. Linking population viability, habitat suitability, and landscape simulation models for conservation planning. Ecol. Model. 2004, 180, 103-118.

66. Barker, R.; King, D.J. Blanding's Turtle (Emydoidea blandingii) Potential Habitat Mapping in Gatineau Park, Quebec, Using High Resolution Ortho Photos. In Proceedings of 30th Canadian Symposium on Remote Sensing, Lethbridge, AB, Canada, 22-26 June 2009; Paper 555, pp. 616-624.

67. MacAlister, C.; Mahaxay, M. Mapping wetlands in the Lower Mekong Basin for wetland resource and conservation management using Landsat ETM images and field survey data. J. Environ. Manage. 2009, 90, 2130-2137.

68. Castaneda, C.; Ducrot, D. Land cover mapping of wetland areas in agricultural landscape using SAR and Landsat imagery. J Environ. Manage. 2009, 90, 2270-2277.

69. Jollineau, M.Y.; Howarth, P.J. Mapping an inland wetland complex using hyperspectral imagery. Int. J. Remote Sens. 2008, 29, 3609-3631.

70. Maxa, M.; Bolstad, B. Mapping northern wetlands with high resolution satellite images and LiDAR. Wetlands 2009, 29, 248-260.

71. Dechka, J.A.; Franklin, S.E.; Watmough, M.D.; Bennett, R.P.; Ingstrup, D.W. Classification of wetland habitat and vegetation communities using multi-temporal IKONOS imagery in southern Saskatchewan. Can. J. Remote Sens. 2002, 28, 679-685.

72. Gilmore, M.S.; Wilson, E.H.; Barett, N.; Civco, D.L.; Prisloe, S.; Hurd, J.D.; Chadwick, C. Integrating multi-temporal spectral and structural information to map wetland vegetation in a lower Connecticut River tidal marsh. Remote Sens. Environ. 2008, 112, 4048-4060.

73. Dogan, O.K.; Akyurek, Z.; Beklioglu, M. Identification and mapping of submerged plants in a shallow lake using Quickbird satellite data. J. Environ. Manage. 2009, 90, 2138-2143.

74. Yuan, L.; Zhang, L. Mapping large-scale distribution of submerged aquatic vegetation coverage using remote sensing. Ecol. Inform. 2008, 3, 245-251.

75. Garden, G.J.; McAlpine, C.A.; Possingham, H.P. Multi-scaled habitat considerations for conserving urban biodiversity: Native reptiles and small mammals in Brisbane, Australia. Landscape Ecol. 2010, 25, 1013-1028.

76. Santos, X.; Brito, J.C.; Sillero, N.; Pleguezuelos, J. M.; Llorente, G.A.; Fahd, S.; Parellada, X. Inferring habitat-suitability areas with ecological modelling techniques and GIS: A contribution to assess the conservation status of Vipera latastei. Biol. Conserv. 2006, 130, 416-425.

77. Harvey, K.R.; Hill, G.J. Mapping the nesting habitats of saltwater crocodiles (Crocodylus porosus) in Melacca Swamp and the Adelaide River wetlands, Northern Territory: An approach using remote sensing and GIS. Wildlife Res. 2003, 30, 365-375.

78. Yu, Q.; Gong, P.; Clinton, N.; Biging. G.; Kelly, M.; Schirokauer, D. Object-based detailed vegetation classification with airborne high spatial resolution remote sensing imagery. Photogramm. Eng. Remote Sensing 2006, 72, 799-811. 
79. Hogg, A.R.; Todd, K.W. Automated discrimination of upland and wetland using terrain derivatives. Can. J. Remote Sens. 2007, 33, s68-s83.

(C) 2012 by the authors; licensee MDPI, Basel, Switzerland. This article is an open access article distributed under the terms and conditions of the Creative Commons Attribution license (http://creativecommons.org/licenses/by/3.0/). 